\title{
The optimal degree of lateral wedge insoles for reducing knee joint load: a systematic review and meta-analysis
}

\author{
Vitor Ferreira" ${ }^{*}$, Rita Simões $^{2}$, Rui Soles Gonçalves ${ }^{3}$, Leandro Machado ${ }^{4}$ and Paulo Roriz ${ }^{5}$
}

\begin{abstract}
Background: Lateral wedge insoles are traditionally used to reduce the adduction moment that crosses the knee during walking in people with medial knee osteoarthritis. However, the best degree to reduce knee joint load is not yet well established.

Methods: Electronic databases were searched from their inception until May 2017. Included studies reported on the immediate biomechanical effects of different degrees of lateral wedge insoles during walking in people with knee osteoarthritis. The main measures of interest relating to the biomechanics were the first and second peak of external knee adduction moment and knee adduction angular impulse. For the comparison of the biomechanical effects of different degrees of insoles, the studies were divided in three subgroups: insoles with a degree higher than $0^{\circ}$ and equal to or lower than $5^{\circ}$; insoles higher than $5^{\circ}$ and equal to or lower than $9^{\circ}$; and insoles higher than $9^{\circ}$. Eligible studies were pooled using random-effects meta-analysis.

Results: Fifteen studies with a total of 415 participants met all eligibility criteria and were included in the final review and meta-analysis. The overall effect suggests that lateral wedge insoles resulted in a statistically significant reduction in the first peak (standardized mean difference $[S M D]-0.25 ; 95 \%$ confidence interval $[\mathrm{Cl}]-0.36,-0.13$; $P<0.001$ ), second peak (SMD $-0.26[95 \% \mathrm{Cl}-0.48,-0.04] ; P=0.02$ ) and knee adduction angular impulse (SMD -0.17 $[95 \% \mathrm{Cl}-0.31,-0.03] ; \mathrm{P}=0.02)$. The test of subgroups found no statistically significant differences.

Conclusion: Systematic review and meta-analysis suggests that lateral wedge insoles cause an overall slight reduction in the biomechanical parameters. Higher degrees do not show higher reductions than lower degrees. Prior analysis of biomechanical parameters may be a valid option for selecting the optimal angle of wedge that best fits in knee osteoarthritis patients with the lowest possible degree.
\end{abstract}

Keywords: Lateral wedge insoles, External knee adduction moment, Osteoarthritis, Knee, Meta-analysis

\section{Background}

Knee osteoarthritis (OA) is one of the most common forms of arthritis and is a leading cause of disability in older adults $[1,2]$. Joint loads during walking are implicated in the pathogenesis of knee OA [3]. The ground reaction force (GRF) vector and the corresponding position vector, relative to the knee joint center, contribute to quantify the knee joint reaction force and illustrate better how load is distributed across the knee

\footnotetext{
* Correspondence: v.ferreira@ua.pt

${ }^{1}$ School of Health Sciences, ESSUA - School of Health, Edificio 30, University of Aveiro, 3810-193 Aveiro, Portugal

Full list of author information is available at the end of the article
}

compartments. In fact, the external knee adduction moment (EKAM), mainly used in the study of knee OA, is obtained from the cross product between the frontal plane components of the previous vectors. During walking, the forces across the knee are not transmitted equally between the medial and lateral compartments [4]. The medial compartment has a higher load prevalence in subjects with tibiofemoral OA relative to the lateral compartment, especially in men [5]. A reduction in the EKAM leads to a change in medial-to-lateral distribution and a relative lowering of the internal forces in the medial compartment [6].

(c) The Author(s). 2019 Open Access This article is distributed under the terms of the Creative Commons Attribution 4.0 International License (http://creativecommons.org/licenses/by/4.0/), which permits unrestricted use, distribution, and 
Yasuda and Sasaki, in the 1980s, originally described the potential of lateral wedged insoles to manage medial knee OA [7]. Lateral wedge insoles are placed inside shoes and shift the point of application of the GRF toward the outside of the foot (laterally), reducing the moment arm (i.e., the position vector that is normal to the GRF vector) during walking [8]. Therefore, the magnitude of the EKAM is also reduced, leading not only to a redistribution of knee load but also to a reduction of the load at the medial compartment $[9,10]$. However, a current meta-analysis demonstrated that lateral wedge insoles caused small reductions in the EKAM and knee adduction angular impulse (KAAI) during walking, which could be ineffective in people with medial knee OA [11]. Moreover, it is estimated that at least $20 \%$ of the individuals using lateral wedge insoles could even increase EKAM during gait [8,12-15]. Nevertheless, it is reasonable to argue that some factors may have affected the previous outcomes, such as the type of insole and the wedge degree. Several variations of the insole have been described, ranging from a wedge only on the heel [16-18] to one on the whole foot [19-21] and with [22-24] or without arch support [25-27]. On the other hand, most of the studies have been performed using the same wedge degree for all individuals, typically a 5 or 6 wedge degree $[13,20,28,29]$. This lack of customization of insoles has been proposed as a relevant research question in an Arnold's Editorial Journal article, "One size fits all, some or none?" [30]. Certainly, it is a question that needs more research.

To our knowledge, no systematic review pursues an understanding of the effects of the amount of wedge insole angulation on biomechanical factors associated with medial knee OA. Reviews have sought to distinguish the effects on biomechanics, but only on the global effect of several types of angulations [11] or on the influence of an arch support in the wedge insoles [31]. Therefore, the main objective of the present review was to determine the biomechanical effects of lateral wedge insoles of different angles in people with knee OA and attempt to understand whether any angulation is more effective in improving biomechanical parameters in patients with knee OA.

\section{Methods}

A systematic literature search was conducted, following the Preferred Reporting Items for Systematic Reviews and Meta-Analyses (PRISMA) group statement [32]. The study protocol is registered in PROSPERO (International prospective register of systematic reviews), with registration number CRD42017070785 (http://www.crd. york.ac.uk/prospero/).

The Population, Intervention, Comparison, and Outcome (PICO) framework was used to define the search strategy [33]: P (population) individuals diagnosed with knee osteoarthritis; I (intervention) that used lateral wedge insoles; $\mathrm{C}$ (comparison) who wore neutral insoles or their own shoes; O (outcome) first peak EKAM, second peak EKAM and KAAI when available.

Combinations of keywords and specific subject headings related to knee osteoarthritis, external knee adduction moment, biomechanics kinetics and kinematics, and interventions to reduce dynamic loading of the knee were employed.

Boolean operators "OR" and "AND" were used to combine search terms. No restrictions were set for the searches with respect to language or publication year. Two investigators (VF, RS) developed the search strategy (Table 1) and completed the systematic search. Medline/ PubMed, CINAHL, and Scopus were searched from their inception through May 31, 2017. Syntax was adjusted appropriately for use in multiple databases. Keywords were identical for all searches. Keywords Medical Subject Headings (MeSH) proofed and non-MeSH proofed were used to increase the chances of finding the intended studies.

\section{Eligibility criteria}

The articles from those databases were collected, and duplicates were removed and cross-checked between the researchers to ensure agreement. Two authors (VF, RS) reviewed the titles and abstracts of all articles for eligibility based on the criteria list. When in doubt, full-text articles were reviewed. Disagreements were resolved by discussion until consensus was reached.

Studies to be included in this review must have been peer-reviewed studies that examined the acute biomechanical effects of laterally wedged insoles in patients with medial compartment knee OA, published as full text. There were no restrictions on design and severity of knee OA. Studies must have investigated a lateral wedged insole, defined as an in-shoe orthotic device with

Table 1 Example of MEDLINE search strategy

\begin{tabular}{ll}
\hline Search & Query \\
\hline 1 & knee \\
2 & arthritis OR arthrosis OR osteoarthr* \\
3 & 1 AND 2 \\
4 & biomechanic* OR kinematics* OR kinetics* \\
5 & 3 AND 4 \\
6 & adduction moment \\
7 & ekam* OR kam* OR varus moment* OR knee varus* \\
8 & 6 OR 7 \\
9 & lateral* OR wedge* OR insole* \\
10 & 5 AND 8 \\
11 & 9 AND 10 \\
\hline
\end{tabular}


a degree of inclination toward the lateral border of the foot. No restrictions were made regarding the features of insoles (i.e., length: heel or full length) or presence of concurrent arch support in the device. Only baseline data inferring the immediate effects of lateral wedge insoles were used. Studies must have included a comparison condition that could be the insole removed or neutral insole (without any degree). If studies included the two control conditions (neutral insole or insole removed), only the data from neutral insole were analyzed. If an article analyzed customization intervention, but did not provide individual results, the article was excluded.

Systematic and narrative reviews were eligible for the purposes of a manual reference list, searching only to identify any studies missed in the primary search. Studies were excluded if they did not include patients with osteoarthritis or osteoarthrosis, and if they were abstracts, case reports, editorials, conference proceedings papers, study protocols or unpublished papers, or without full access.

\section{Data extraction}

From the full articles that formed the results of this systematic review, the principal author extracted data of the characteristics of the individual trials and all outcomes into spreadsheets. A second author (RS) checked the data for accuracy. The main data extracted was the study design, number of patients, patient characteristics, type of insole, degree of lateral wedge, control condition, biomechanical outcome measures, statistical information, and funding sources. Primary outcome variables of interest extracted included features of the external knee adduction moment: the first peak EKAM, second peak EKAM, and KAAI.

\section{Assessment of risk of bias in included studies}

The risk-of-bias assessment was completed by one author (VF) and checked by a second author (RS), using the Cochrane Risk of Bias assessment tool [34]. Each article was graded (unclear, low, or high risk of bias) based on selection bias (random sequence generation and allocation concealment), detection bias (blinding of outcome assessment), blinding of participants and personnel (performance bias), attrition bias (incomplete outcome data), reporting bias (selective reporting), and other bias. In case of disagreements, a common consensus was established and a third author (PR) was consulted if consensus could not be reached after consulting the guidelines of the software used.

\section{Data analysis}

Statistical information, including descriptive (means, medians, standard deviations [SDs], change scores) and inferential $(P$ values, confidence interval $[\mathrm{CI}])$ information, was extracted and cross-checked by two authors (VF, RS). For the meta-analysis, standardized mean differences (SMDs) were calculated as the mean difference in EKAM change produced by the degree of the insole and the control (neutral insole or without insole), divided by the pooled standard deviation of the measurement. Hence, a negative effect size indicated a beneficial effect for the insole group. Effect sizes were interpreted as 0.2 (small), 0.5 (medium), and 0.8 (large) [35]. Meta-analysis was performed in Review Manager (RevMan) software (version 5.3, Cochrane Collaboration), using the inverse variance method [36], where the contribution of effect sizes from individual studies was weighted on sample size. For studies not reporting enough data, and where the authors could not provide data, they were calculated from other available data when possible (e.g., from 95\% CI or $P$ values from $t$-tests). It was decided to use a random-effects model, a priori, to estimate the pooled effect of intervention more conservatively.

Heterogeneity was assessed using a $\chi^{2}$ test ( $\mathrm{Q}$ value), its corresponding degrees of freedom, and $p$ value. The extent of heterogeneity was analyzed using Higgins' $I^{2}$ value (expressed as \%) [37]. Heterogeneity determined the percentage of total variation across studies that is due to heterogeneity rather than to chance and examines the null hypothesis that all studies are evaluating the same effect [38]. For the interpretation of heterogeneity, the values of 25,50 , and $75 \%$ were followed, which represent low, moderate, and high heterogeneity, respectively [38]. The risk of small-study effects was assessed using the Egger's regression test [34] and, if present, adjustment was planned using a trim-and-fill method [39] with STATA software (version 12, StataCorp).

\section{Results}

\section{Study selection and characteristics}

A total of 597 records were identified, and 399 were screened on title and abstract. After assessing eligibility against the criteria, 26 studies were retained for full-text review. Fifteen studies, with a total of 415 participants, met all eligibility criteria and were included in the final review and meta-analysis (Fig. 1).

Values are indicated as mean $\pm \mathrm{SD}$ unless indicated otherwise; $\mathrm{M}$ : $\mathrm{F}=$ male: female; $(\mathrm{y})$ years; $\mathrm{K} / \mathrm{L}=$ Kellgren/ Lawrence; $\mathrm{n} / \mathrm{r}$ - not reported.

Table 2 summarizes the characteristics of the included studies and participants. Seven studies had small samples sizes $(n<20)[9,15,18,25,40,41,44]$. Most studies included participants aged over 45 years. The mean age was about the sixties. The principal criterion to classify OA severity was the Kellgren and Lawrence (K/L) scale [46]. Seven studies included only participants with grade 2 or 3 on the K/L scale $[8,13,18,20,24,25,44,45]$. One study used an intervention with an insole of 4 


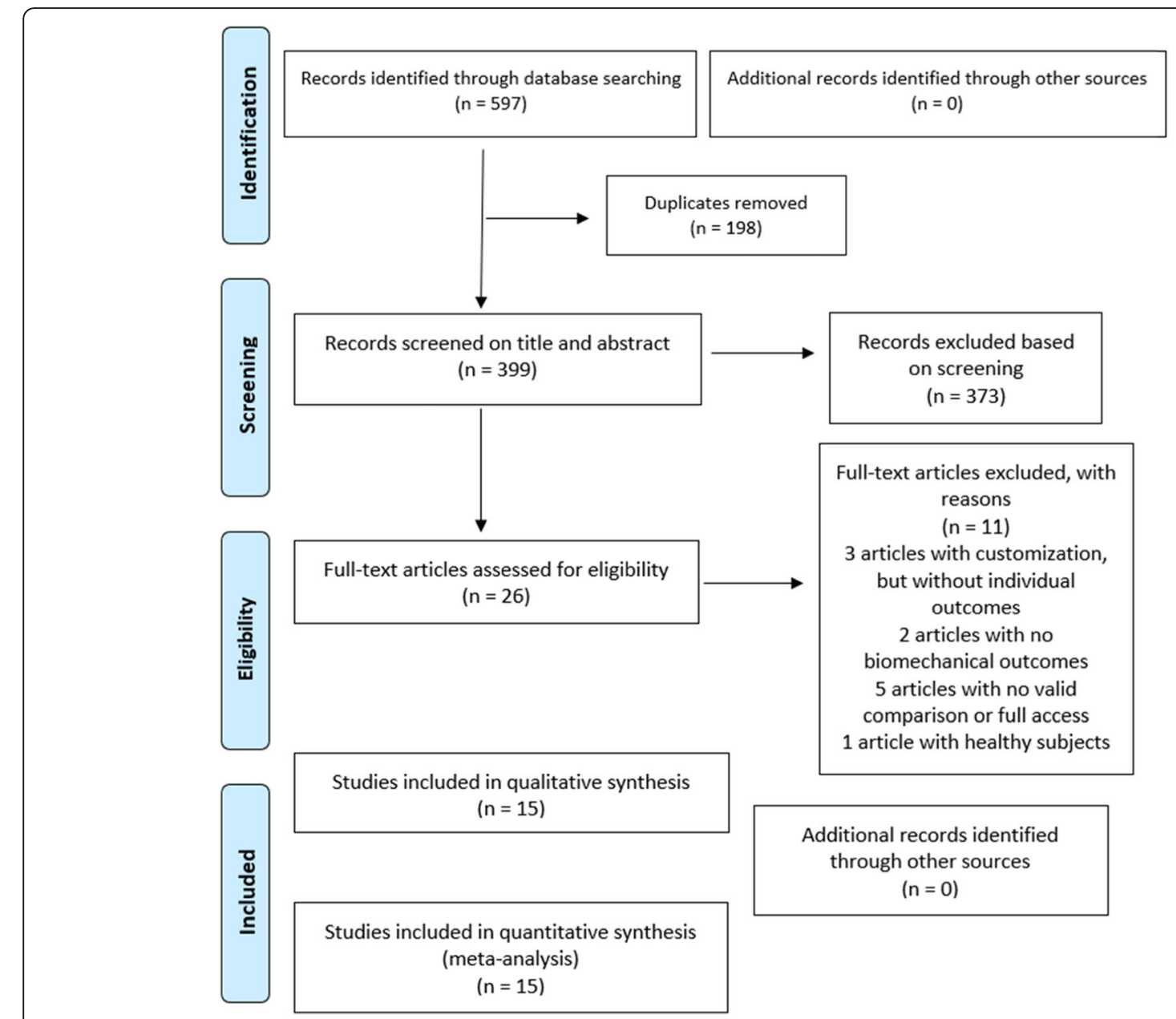

Fig. 1 PRISMA flow diagram of the study selection process

degrees [44], eight studies used an intervention with an insole of 5 degrees $[8,9,13,18,20,40,43,45]$, five studies used an insole of 6 degrees [15, 24-26, 41, 42], two studies with an insole of 10 degrees $[9,25]$, and one study used an insole of 11 degrees [24]. A neutral insole was the comparison condition in four studies $[9,24,25,41]$; nine studies used participants' shoes $[8,15,18,20,26,40,42-44]$, and two used control shoes $[13,45]$. For the comparison of the biomechanical effects of different degrees of insoles, the studies were divided into three subgroups: comparison of interventions with insoles with a degree higher than $0^{\circ}$ and equal to or lower than $5^{\circ}$ (insole $\leq 5^{\circ}$ ); comparison of interventions with insoles higher than $5^{\circ}$ and equal to or lower than $9^{\circ}$ (insole $>5^{\circ}$ and $\leq 9^{\circ}$ ); and comparisons of interventions with insoles higher than $9^{\circ}$ (insole $>9^{\circ}$ ). These intervals were chosen because they have been the most studied in the literature.

\section{Risk of bias}

Inter-rater agreement for each item of the methodological quality assessment was moderate to high $(\mathrm{k}=0.72$ to 0.91$)$. In $71 \%$ of trials, the random sequence generation had adequate or unclear risk of bias. Adequate allocation concealment was observed as low risk of bias in $19 \%$, unclear in $52 \%$, and high risk of bias in $29 \%$ of the included trials. Most of the studies were not blinded to the participants, personnel, or the outcome assessment, but the review authors' judgement remained that the outcome was not likely to be influenced by lack of blinding because, in this type of evaluation, the data processing was carried out later. Therefore, the performance and the detection bias were considered $100 \%$ adequate. Incomplete outcome data were presented in $5 \%$ of the trials, and selective reporting was observed as low risk of bias in $86 \%$ of the trials (see Additional files 1 and 2).

SMD: standardized mean differences; Nm/kg: Newtonmeter / kilogram; \%BW*Ht: \% body weight $\mathrm{x}$ height; mm: millimeter.

\section{Meta-analysis}

The first peak EKAM was the major outcome reported in the studies. All 15 studies stated the first peak EKAM. 
Table 2 Characteristics of included studies $(n=15)$

\begin{tabular}{|c|c|c|c|c|c|c|c|c|c|}
\hline \multirow[t]{2}{*}{ Authors (year) } & \multirow[t]{2}{*}{$n$} & \multirow[t]{2}{*}{$\begin{array}{l}\text { Sex } \\
\text { M:F }\end{array}$} & \multirow[t]{2}{*}{ Age (y) } & \multirow{2}{*}{$\begin{array}{l}\text { Varus } \\
\text { alignment } \\
\left({ }^{\circ}\right)\end{array}$} & \multicolumn{4}{|c|}{$\begin{array}{l}\text { K/L Grade } \\
\text { severity }(n)\end{array}$} & \multirow[t]{2}{*}{ Funding Source } \\
\hline & & & & & $\overline{1}$ & 2 & 3 & 4 & \\
\hline Kerrigam et al. [9] (2002) & 15 & $8: 7$ & $69.7 \pm 7.6$ & $n / r$ & 0 & 0 & 10 & 5 & $\begin{array}{l}\text { Supported by the Ellison Foundation and by } \\
\text { the US Public Health Service. }\end{array}$ \\
\hline Maly et al. [40] (2002) & 12 & $9: 3$ & $60 \pm 9.39$ & $6.67 \pm 4.2$ & $\mathrm{n} /$ & $\begin{array}{l}\mathrm{n} / \\
\mathrm{r}\end{array}$ & $\begin{array}{l}\mathrm{n} / \\
\mathrm{r}\end{array}$ & $\mathrm{n} /$ & $\begin{array}{l}\text { Drummond Foundation and the Natural Sciences and } \\
\text { Engineering Research Council of Canada. }\end{array}$ \\
\hline Kakihana et al. [41] (2005) & 13 & $n / r$ & $63.3 \pm 5.6$ & $2.5 \pm 3.9$ & $\mathrm{n} / \mathrm{r}$ & $\mathrm{n} /$ & $\begin{array}{l}n / \\
r\end{array}$ & $\mathrm{n} /$ & Not stated \\
\hline Shimada et al. [42] (2006) & 23 & $6: 17$ & $67.0 \pm 8.7$ & $6.2 \pm 4.4$ & 11 & 11 & 13 & 11 & Not stated \\
\hline Hinman et al. [43] (2008a) & 40 & $\begin{array}{l}16: \\
24\end{array}$ & $64.7 \pm 9.4$ & $5.5^{\circ}$ & 3 & 10 & 11 & 16 & University Grants and the Arthritis Foundation of Australia. \\
\hline Hinman et al. [18] (2008b) & 13 & $6: 7$ & $59.7 \pm 6.2$ & $1.9^{\circ} \pm 2.9$ & 0 & 7 & 6 & 0 & National Health and Medical Research Council of Australia \\
\hline Hinman et al. [20] (2009) & 20 & $8: 12$ & $63.5 \pm 9.4$ & $n / r$ & 0 & 8 & 12 & 0 & $\begin{array}{l}\text { National Health \& Medical Research Council of Australia and } \\
\text { the ANZ Charitable Trusts }\end{array}$ \\
\hline $\begin{array}{l}\text { Abdallah and Radwan [24] } \\
\text { (2011) }\end{array}$ & 21 & $0: 21$ & $54.1 \pm 7.4$ & $176-180^{\circ}$ & 0 & $\begin{array}{l}\mathrm{n} / \\
\mathrm{r}\end{array}$ & $\begin{array}{l}\mathrm{n} / \\
\mathrm{r}\end{array}$ & 0 & Not stated \\
\hline Hinman et al. [8] (2012) & 73 & $\begin{array}{l}28: \\
45\end{array}$ & $63.3 \pm 8.4$ & $0.9^{\circ}$ valgus & 0 & 41 & 32 & 0 & National Health \& Medical Research Council of Australia \\
\hline Pagani et al. [44] (2012) & 10 & $2: 8$ & $57.5 \pm 7.1$ & $2.1^{\circ} \pm 1.2$ & 0 & 6 & 4 & 0 & $\begin{array}{l}\text { Institute of Biomechanics of the German Sport } \\
\text { University Cologne. }\end{array}$ \\
\hline Jones et al. [13] (2014) & 70 & $\begin{array}{l}43: \\
27\end{array}$ & $60.3 \pm 9.6$ & $n / r$ & 0 & 17 & 25 & 0 & $\begin{array}{l}\text { Arthritis Research UK and National Institute for Health } \\
\text { Research Biomedical Research Unit Funding Scheme. }\end{array}$ \\
\hline $\begin{array}{l}\text { Duivenvoorden et al. [26] } \\
\text { (2015) }\end{array}$ & 42 & $\begin{array}{l}14: \\
28\end{array}$ & $54.0 \pm 7.0$ & $n / r$ & 15 & 8 & 18 & 1 & Not stated \\
\hline Hatfield et al. [45] (2016) & 26 & $4: 22$ & $64.0 \pm 8.0$ & $n / r$ & 0 & 16 & 10 & 0 & $\begin{array}{l}\text { Pedorthic Foundation of Canada. Canadian Institutes of } \\
\text { Health Research the Natural Sciences and Engineering } \\
\text { Research Council of Canada, and the Michael Smith } \\
\text { Foundation for Health Research }\end{array}$ \\
\hline Dessery et al. [25] (2016) & 18 & $8: 10$ & $54.5 \pm 8.6$ & $4.5^{\circ} \pm 2.8$ & 0 & 15 & 3 & 0 & $\begin{array}{l}\text { Fonds de Recherche du Québec - Nature et Technologies. } \\
\text { Natural Sciences and Engineering Research Council of Canada. } \\
\text { Ergoresearch Inc }\end{array}$ \\
\hline Lewinson et al. [15] (2016) & 19 & $6: 13$ & $59.9 \pm 7.4$ & $n / r$ & 5 & 2 & 3 & 9 & $\begin{array}{l}\text { Canadian Institutes of Health Research. Alberta Innovates } \\
\text { Health Solutions. Killam Trusts. New Balance Athletic Shoe Inc }\end{array}$ \\
\hline
\end{tabular}

Because some studies made multiple comparisons with different features of the insole, such as the arch support or the length of the wedge, a total of 21 comparisons were included in the meta-analysis for the first peak EKAM (see Table 3). The overall effect suggests that lateral wedge insoles resulted in a statistically significant reduction in the first peak EKAM $(n=578$, SMD -0.25 [95\% CI $-0.36,-0.13], P<0.001)$, with a low level of statistical heterogeneity $\left(x^{2}=5.44, P=1.00, I^{2} 0 \%\right.$ ) (Fig. 2).

The comparison for subgroups did not show a statistically significant difference $\left(x^{2}=0.31, P=0.85, I^{2} 0 \%\right)$. Two subgroups presented statistically significant reductions: insole $\leq 5^{\circ}$ (SMD -0.22 [95\% CI $-0.37,-0.08$ ], $\left.P=0.002\right)$ and insole $>5^{\circ}$ and $\leq 9^{\circ}(\mathrm{SMD}-0.29$ [95\% CI $-0.53,-0.05], P=$ $0.02)$. However, the subgroup insole $>9^{\circ}$ showed no statistically significant reduction (SMD -0.30 [95\% CI -0.68 , 0.08], $P=0.12$ ). The Egger's regression test for funnel plot asymmetry was positive $(\beta=-0.75$, standard error (SE) $0.33, P=0.034)$, indicating weak evidence of publication bias for the first peak EKAM (see Additional file 3). When using the trim and fill method, no trimming was performed, and the data remained unchanged.

Only six studies reported the second peak EKAM $[9,18,20,25,43,44]$. A total of nine comparisons were included in the data synthesis (Table 3). Six comparisons were for insoles $\leq 5^{\circ}$. The overall effect suggests that lateral wedge insoles resulted in a statistically significant reduction in the second peak EKAM $(n=162$, SMD -0.26 [95\% CI $-0.48,-0.04], P=0.02)$, with a low level of statistical heterogeneity $\left(x^{2}=0.39, P=1.00, I^{2} 0 \%\right)$ (Fig. 3).

None of the subgroups showed a statistically significant reduction of the overall effect, with pooled effect similar between them when compared with the control condition: insole $\leq 5^{\circ}$ (SMD -0.24 [95\% CI $-0.50,0.03$ ], $\left.P=0.08\right)$; insole $>5^{\circ}$ and $\leq 9^{\circ}$ (SMD -0.27 [95\% CI $-0.92,0.39$ ], $P=$ $0.43)$; and insole $>9^{\circ}$ (SMD -0.32 [95\% CI -0.80, 0.17], $P=0.2$ ). Egger's regression test for funnel plot asymmetry was not statistically significant, indicating weak evidence 
Table 3 Comparisons of interventions of included studies

\begin{tabular}{|c|c|c|c|c|}
\hline \multirow[t]{2}{*}{ Authors (year) } & \multirow{2}{*}{$\begin{array}{l}\text { Unit of } \\
\text { measure }\end{array}$} & \multicolumn{2}{|l|}{ Comparisons } & \multirow[t]{2}{*}{ SMD $(95 \% \mathrm{Cl})$} \\
\hline & & Intervention & Control & \\
\hline \multicolumn{5}{|l|}{ First peak EKAM } \\
\hline Kerrigam et al. [9] (2002)a & $\mathrm{Nm} / \mathrm{Kg}^{*} \mathrm{~m}$ & $5^{\circ}$ insole & $5^{\circ}$ Control insole $(3.175 \mathrm{~mm})$ & $-0.17[-0.88,0.55]$ \\
\hline Kerrigam et al. [9] (2002)b & $\mathrm{Nm} / \mathrm{Kg}^{*} \mathrm{~m}$ & $10^{\circ}$ insole & $10^{\circ}$ Control insole $(6.35 \mathrm{~mm})$ & $-0.37[-1.09,0.36]$ \\
\hline Maly et al. [40] (2002) & $\mathrm{Nm} / \mathrm{Kg}$ & $5^{\circ}$ insole & Participant shoes & $-0.08[-0.88,0.72]$ \\
\hline Kakihana et al. [41] (2005) & $\mathrm{Nm} / \mathrm{Kg}$ & $6^{\circ}$ insole & Neutral insole & $-0.97[-1.79,-0.15]$ \\
\hline Shimada et al. [42] (2006) & $\mathrm{Nm} / \mathrm{Kg}$ & $6^{\circ}$ insole & Participant shoes & $-0.20[-0.78,0.38]$ \\
\hline Hinman et al.) [43] (2008a & $\% \mathrm{BW}^{*} \mathrm{Ht}$ & $5^{\circ}$ insole & Participant shoes & $-0.21[-0.65,0.23]$ \\
\hline Hinman et al. [18] (2008b)a & $\% \mathrm{BW}^{*} \mathrm{Ht}$ & $5^{\circ}$ full-length wedges & Participant shoes & $-0.54[-1.33,0.24]$ \\
\hline Hinman et al. [18] (2008b)b & $\% \mathrm{BW}^{*} \mathrm{Ht}$ & $5^{\circ}$ rearfoot wedges & Participant shoes & $-0.33[-1.10,0.45]$ \\
\hline Hinman et al. [20] (2009) & $\% \mathrm{BW}^{*} \mathrm{Ht}$ & $5^{\circ}$ insole & Participant shoes & $-0.33[-1.10,0.45]$ \\
\hline Abdallah and Radwan [24] (2011)a & $\mathrm{Nm} / \mathrm{Kg}$ & $6^{\circ}$ insole & Neutral insole & $-0.18[-0.79,0.42]$ \\
\hline Abdallah and Radwan [24] (2011)b & $\mathrm{Nm} / \mathrm{Kg}$ & $11^{\circ}$ insole & Neutral insole & $-0.32[-0.93,0.29]$ \\
\hline Hinman et al. [8] (2012) & $\% \mathrm{BW}^{*} \mathrm{Ht}$ & $5^{\circ}$ insole & Participant shoes & $-0.29[-0.61,0.04]$ \\
\hline Pagani et al. [44] (2012) & $\mathrm{Nm} / \mathrm{Kg}$ & $4^{\circ}$ insole & Participant shoes & $-0.20[-1.08,0.67]$ \\
\hline Jones et al. [13] (2014)a & $\mathrm{Nm} / \mathrm{Kg}$ & $5^{\circ}$ insole with arch support & Control shoes & $-0.16[-0.49,0.17]$ \\
\hline Jones et al. [13] (2014)b & $\mathrm{Nm} / \mathrm{Kg}$ & $5^{\circ}$ insole without arch support & Control shoes & $-0.17[-0.50,0.17]$ \\
\hline Duivenvoorden et al. [26] (2015) & $\mathrm{Nm} / \mathrm{kg}$ & $6^{\circ}$ insole & Participant shoes & $-0.12[-0.55,0.31]$ \\
\hline Hatfield et al. [45] (2016)a & $\mathrm{Nm} / \mathrm{kg}$ & $5^{\circ}$ insole with arch support & Control shoes & $-0.19[-0.74,0.35]$ \\
\hline Hatfield et al. [45] (2016)b & $\mathrm{Nm} / \mathrm{kg}$ & $5^{\circ}$ insole without arch support & Control shoes & $-0.25[-0.80,0.29]$ \\
\hline Dessery et al. [25] (2016)a & $\% \mathrm{BW}^{*} \mathrm{Ht}$ & $6^{\circ}$ insole with arch support & Control insole & $-0.42[-1.08,0.24]$ \\
\hline Dessery et al. [25] (2016)b & $\% \mathrm{BW}^{*} \mathrm{Ht}$ & $10^{\circ}$ insole with arch support & Control insole & $-0.23[-0.88,0.43]$ \\
\hline Lewinson et al. [15] (2016) & $\mathrm{Nm}$ & $6^{\circ}$ insole & Participant shoes & $-0.38[-1.03,0.26]$ \\
\hline \multicolumn{5}{|l|}{ Second peak EKAM } \\
\hline Kerrigam et al. [9] (2002)a & $\mathrm{Nm} / \mathrm{Kg}^{*} \mathrm{~m}$ & $5^{\circ}$ insole & $5^{\circ}$ Control insole $(3.175 \mathrm{~mm})$ & $-0.17[-0.89,0.55]$ \\
\hline Kerrigam et al. [9] (2002)b & $\mathrm{Nm} / \mathrm{Kg}^{*} \mathrm{~m}$ & $10^{\circ}$ insole & $10^{\circ}$ Control insole $(6.35 \mathrm{~mm})$ & $-0.30[-1.02,0.42]$ \\
\hline Hinman et al. [43] (2008a) & $\% \mathrm{BW}^{*} \mathrm{Ht}$ & $5^{\circ}$ insole & Participant shoes & $-0.31[-0.75,0.13]$ \\
\hline Hinman et al. [18] (2008b)a & $\% \mathrm{BW}^{*} \mathrm{Ht}$ & $5^{\circ}$ full-length wedges & Participant shoes & $-0.34[-1.12,0.43]$ \\
\hline Hinman et al. [18] (2008b)b & $\% \mathrm{BW}^{*} \mathrm{Ht}$ & $5^{\circ}$ rearfoot wedges & Participant shoes & $-0.17[-0.94,0.60]$ \\
\hline Hinman et al. [20] (2009) & $\% \mathrm{BW}^{*} \mathrm{Ht}$ & $5^{\circ}$ insole & Participant shoes & $-0.16[-0.78,0.46]$ \\
\hline Pagani et al. [44] (2012) & $\mathrm{Nm} / \mathrm{Kg}$ & $4^{\circ}$ insole & Participant shoes & $-0.18[-1.06,0.70]$ \\
\hline Dessery et al. [25] (2016)a & $\% \mathrm{BW}^{*} \mathrm{Ht}$ & $6^{\circ}$ insole with arch support & Control insole & $-0.27[-0.92,0.39]$ \\
\hline Dessery et al. [25] (2016)b & $\% \mathrm{BW}^{*} \mathrm{Ht}$ & $10^{\circ}$ insole with arch support & Control insole & $-0.33[-0.99,0.33]$ \\
\hline \multicolumn{5}{|l|}{ Knee adduction angular impulse } \\
\hline Hinman et al. [20] (2009) & $\% \mathrm{BW}^{*} \mathrm{Ht}$ & $5^{\circ}$ insole & Participant shoes & $-0.14[-0.76,0.48]$ \\
\hline Hinman et al. [8] (2012) & $\% \mathrm{BW}^{*} \mathrm{Ht}$ & $5^{\circ}$ insole & Participant shoes & $-0.21[-0.54,0.11]$ \\
\hline Pagani et al. [44] (2012) & $\mathrm{Nm} / \mathrm{Kg}$ & $4^{\circ}$ insole & Participant shoes & $-0.15[-1.03,0.73]$ \\
\hline Jones et al. [13] (2014)a & $\mathrm{Nm} / \mathrm{Kg}$ & $5^{\circ}$ insole with arch support & Control shoes & $-0.14[-0.47,0.19]$ \\
\hline Jones et al. [13] (2014)b & $\mathrm{Nm} / \mathrm{Kg}$ & $5^{\circ}$ insole without arch support & Control shoes & $-0.19[-0.52,0.15]$ \\
\hline Duivenvoorden et al. [26] (2015) & $\mathrm{Nm} / \mathrm{kg}$ & $6^{\circ}$ insole & Participant shoes & $-0.02[-0.45,0.40]$ \\
\hline Hatfield et al. [45] (2016)a & $\mathrm{Nm} / \mathrm{kg}$ & $5^{\circ}$ insole with arch support & Control shoes & $-0.12[-0.66,0.43]$ \\
\hline Hatfield et al. [45] (2016)b & $\mathrm{Nm} / \mathrm{kg}$ & $5^{\circ}$ insole without arch support & Control shoes & $-0.12[-0.66,0.43]$ \\
\hline Dessery et al. [25] (2016)a & $\% \mathrm{BW}^{*} \mathrm{Ht}$ & $6^{\circ}$ insole with arch support & Control insole & $-0.34[-1.00,0.32]$ \\
\hline Dessery et al. [25] (2016)b & $\% \mathrm{BW}^{*} \mathrm{Ht}$ & $10^{\circ}$ insole with arch support & Control insole & $-0.34[-1.00,0.32]$ \\
\hline
\end{tabular}


Table 3 Comparisons of interventions of included studies (Continued)

\begin{tabular}{lllll}
\hline Authors (year) & $\begin{array}{l}\text { Unit of } \\
\text { measure }\end{array}$ & Comparisons & SMD (95\% Cl) \\
\cline { 3 - 4 } & Intervention & Control & \\
\hline Lewinson et al. [15] (2016) & Nms & $6^{\circ}$ insole & Participant shoes & $-0.23[-0.87,0.41]$ \\
\hline
\end{tabular}

of publication bias for the second peak EKAM $(\beta=0.40$, SE 0.36, $P=0.306$ ) (see Additional file 4).

The KAAI was considered in the study of biomechanical risks in past years and was reported in eight studies $[8,13,15,20,25,26,44,45]$. A total of 11 comparisons were included in the data synthesis (Table 3 ). The overall pooled estimate indicated that a statistically significant reduction in the KAAI favors lateral wedge insoles $(n=392$, SMD -0.17 [95\% CI $-0.31,-0.03], P=0.02)$ with a low level of statistical heterogeneity $\left(x^{2}=1.19\right.$, $P=1.00, I^{2}$ 0\%) (Fig. 4). Subgroup comparisons yielded different pooled effects $\left(x^{2}=0.29, P=0.86, I^{2} 0 \%\right)$. The insole $\leq 5^{\circ}$ showed association with KAAI compared to the control condition (SMD -0.17 [95\% CI -0.33 , $0.00], P=0.04$ ). The subgroups insole $>5^{\circ}$ and $\leq 9^{\circ}$ (SMD -0.15 [95\% CI $-0.46,0.17], P=0.36$ ) and insole $>9^{\circ}$
(SMD -0.34 [95\% CI -1.00, 0.32], $P=0.31$ ) showed no associations with KAAI compared to the control condition. The Egger publication bias plot for funnel plot asymmetry was not statistically significant, indicating weak evidence of publication bias for the KAAI ( $\beta=-$ 0.21 , SE 0.34, $P=0.559$ ) (see Additional file 5).

\section{Discussion}

The main objective of this review was to determine the biomechanical effects of different angles of lateral wedge insoles in people with knee OA and understand if different amounts of angulations induce different responses. This meta-analysis confirms that lateral wedge insoles cause an immediate reduction on knee load in conservative treatment for people with medial knee OA. Biomechanical parameters related to the medial knee load,

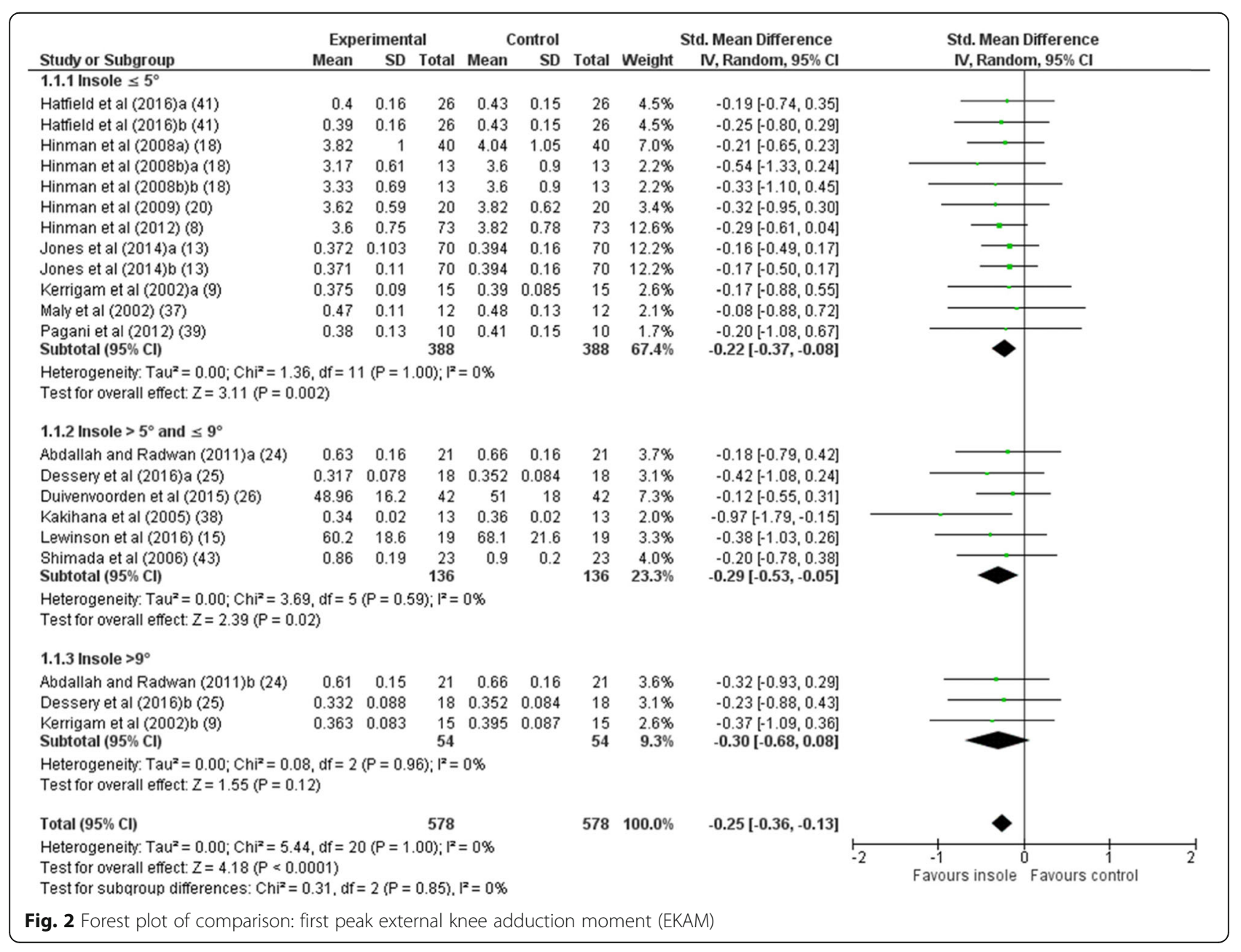




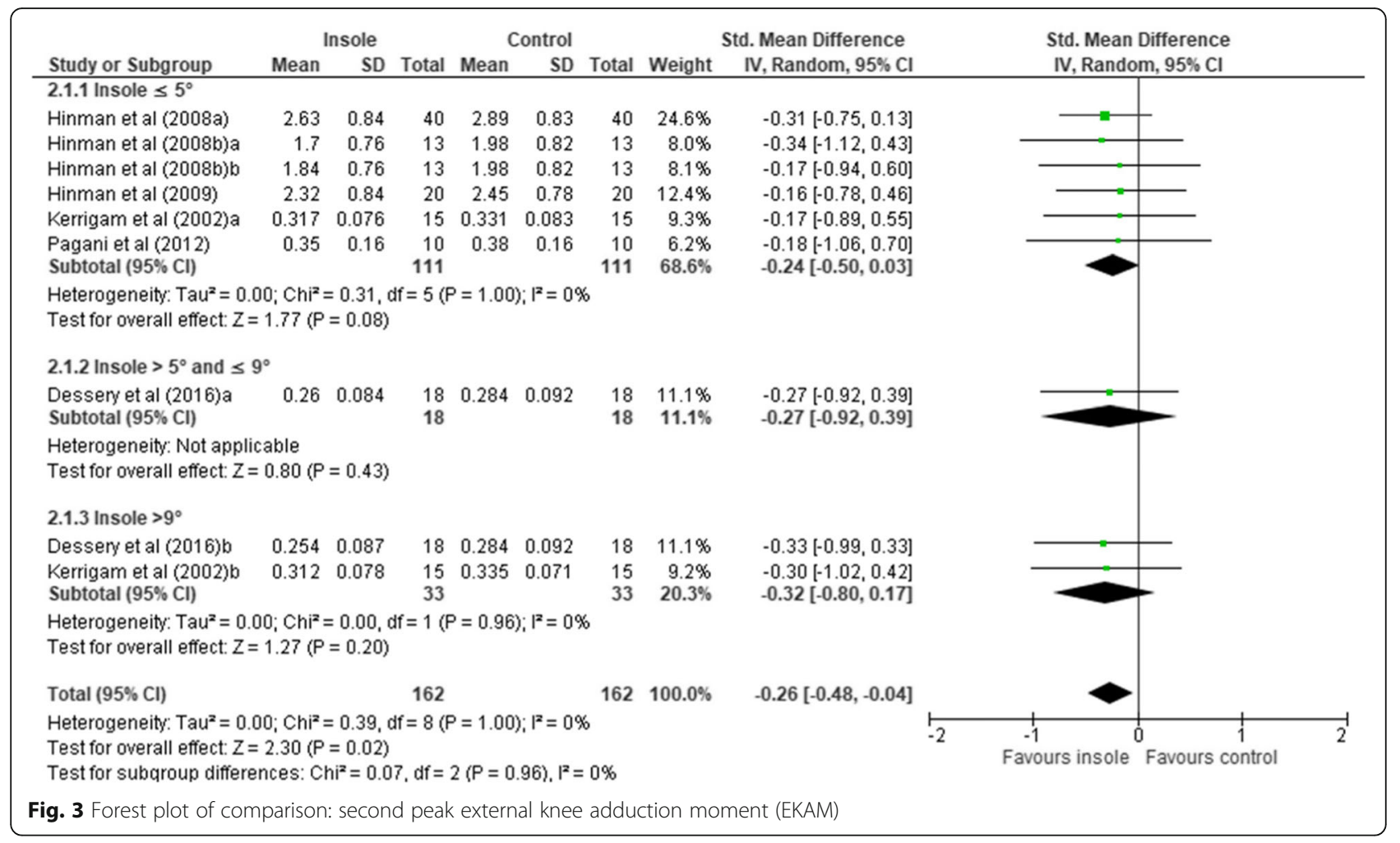

\begin{tabular}{|c|c|c|c|c|c|c|c|c|c|c|c|}
\hline \multirow{3}{*}{$\frac{\text { Study or Subgroup }}{3.1 .1 \text { Insole } \leq 5^{\circ}}$} & \multicolumn{3}{|c|}{ Insole } & \multicolumn{3}{|c|}{ Control } & \multicolumn{2}{|r|}{ Std. Mean Difference } & \multirow{2}{*}{\multicolumn{3}{|c|}{$\begin{array}{l}\text { Std. Mean Difference } \\
\text { IV, Random, } 95 \% \mathrm{Cl}\end{array}$}} \\
\hline & Mean & SD & Total & Mean & SD & Total & Weight & IV, Random, $95 \% \mathrm{Cl}$ & & & \\
\hline & & & & & & & & & & & \\
\hline Hattield et al (2016)a & 0.16 & 0.09 & 26 & 0.17 & 0.08 & 26 & $6.7 \%$ & $-0.12[-0.66,0.43]$ & & & \\
\hline Hattield et al (2016)b & 0.16 & 0.09 & 26 & 0.17 & 0.08 & 26 & $6.7 \%$ & $-0.12[-0.66,0.43]$ & & & \\
\hline Hinman et al (2009) & 1.31 & 0.48 & 20 & 1.38 & 0.49 & 20 & $5.1 \%$ & $-0.14[-0.76,0.48]$ & & & \\
\hline Hinman et al (2012) & 1.18 & 0.38 & 73 & 1.26 & 0.37 & 73 & $18.6 \%$ & $-0.21[-0.54,0.11]$ & & & \\
\hline Jones et al (2014)a & 0.147 & 0.054 & 70 & 0.156 & 0.071 & 70 & $17.9 \%$ & $-0.14[-0.47,0.19]$ & & - & \\
\hline Jones et al (2014)b & 0.144 & 0.056 & 70 & 0.156 & 0.071 & 70 & $17.9 \%$ & $-0.19[-0.52,0.15]$ & & & \\
\hline $\begin{array}{l}\text { Pagani et al }(2012) \\
\text { Subtotal }(95 \% \mathrm{Cl})\end{array}$ & 21.99 & 10.51 & $\begin{array}{r}10 \\
295\end{array}$ & 23.62 & 10.58 & $\begin{array}{r}10 \\
295\end{array}$ & $\begin{array}{r}2.6 \% \\
75.3 \%\end{array}$ & $\begin{array}{r}-0.15[-1.03,0.73] \\
-0.17[-0.33,-0.00]\end{array}$ & & & \\
\hline \multicolumn{12}{|c|}{$\begin{array}{l}\text { Heterogeneity: Tau }{ }^{2}=0.00 ; \mathrm{Ch}^{2}=0.19, \mathrm{df}=6(\mathrm{P}=1.00) ; \mathrm{I}^{2}=0 \% \\
\text { Test for overall effect: } Z=2.01(P=0.04)\end{array}$} \\
\hline \multicolumn{12}{|l|}{ 3.1.2 Insole $>5^{\circ}$ and $\leq 9^{\circ}$} \\
\hline Dessery et al (2016)a & 11.6 & 3.6 & 18 & 12.9 & 3.8 & 18 & $4.5 \%$ & $-0.34[-1.00,0.32]$ & & - & \\
\hline Duivenvoorden et al (2015) & 22.77 & 8.3 & 42 & 23 & 10 & 42 & $10.8 \%$ & $-0.02[-0.45,0.40]$ & & & \\
\hline Lewinson et al (2016) & 28.1 & 10 & $\begin{array}{l}19 \\
79\end{array}$ & 30.5 & 10.7 & $\begin{array}{l}19 \\
79\end{array}$ & $4.8 \%$ & $-0.23[-0.87,0.41]$ & & & \\
\hline \multicolumn{12}{|c|}{$\begin{array}{l}\text { Heterogeneity: } \operatorname{Tau}^{2}=0.00 ; \mathrm{Ch}^{2}=0.72, \mathrm{df}=2(P=0.70) ; \mathrm{I}^{2}=0 \% \\
\text { Test for overall effect: } Z=0.91(P=0.36)\end{array}$} \\
\hline \multicolumn{12}{|l|}{ 3.1.3 Insole $>9^{\circ}$} \\
\hline $\begin{array}{l}\text { Dessery et al }(2016) b \\
\text { Subtotal }(95 \% \mathrm{Cl})\end{array}$ & 11.6 & 3.6 & $\begin{array}{l}18 \\
18\end{array}$ & 12.9 & 3.8 & $\begin{array}{l}18 \\
18\end{array}$ & $\begin{array}{l}4.5 \% \\
4.5 \%\end{array}$ & $\begin{array}{l}-0.34[-1.00,0.32] \\
-0.34[-1.00,0.32]\end{array}$ & & - & \\
\hline \multicolumn{12}{|c|}{$\begin{array}{l}\text { Heterogeneity. Not applicable } \\
\text { Test for overall effect: } Z=1.02(P=0.31)\end{array}$} \\
\hline \multirow{2}{*}{\multicolumn{3}{|c|}{$\begin{array}{l}\text { Total }(95 \% \mathrm{Cl}) \\
\text { Heterogeneity: } \text { Tau }^{2}=0.00 ; \mathrm{Chi}^{2}=1.19, \mathrm{df}=1 \\
\text { Test for overall effect: } \mathrm{Z}=2.37(\mathrm{P}=0.02) \\
\text { Test for subqroup differences: } \mathrm{Chi}^{2}=0.29 \text {, df }\end{array}$}} & 392 & & & 392 & $100.0 \%$ & $-0.17[-0.31,-0.03]$ & & & \\
\hline & & & $\begin{array}{l}0(P=1 \\
=2(P=1\end{array}$ & $\begin{array}{l}1.00) ; 1^{2} \\
=0.86) .\end{array}$ & $\begin{array}{l}=0 \% \\
1^{2}=0 \%\end{array}$ & & & & $\begin{array}{c}-1 \\
\text { Favours insole }\end{array}$ & $\begin{array}{c}1 \\
1 \\
\text { Favours control }\end{array}$ & $\overrightarrow{2}$ \\
\hline ig. 4 Forest plot of compa & ison: Kn & ee add & duction & angula & ar impu & ulse $(K A$ & (AAl) & & & & \\
\hline
\end{tabular}


including first peak EKAM, second peak EKAM, and KAAI were reduced with the use of a lateral wedge insole, apart from the amount of the degree. To the best of our knowledge, no previous reviews evaluated the effect of different angulations on biomechanical parameters. The latest meta-analysis $[11,31]$ regarding these issues did not focus on the effects of different angulations on reducing knee load in people with OA. In the review by Arnold et al. [11], the authors explore the overall effects of lateral wedge insoles on biomechanical risk factors and, in the subgroups analysis, studied the immediate effects among the application of lateral wedge insoles, neutral insoles, or shoes without insoles. In an up-to-date meta-analysis, Xing et al. [31] also studied the immediate effects of lateral wedge insoles, but in the subgroups analysis the authors studied the influence of arch supports on lateral wedge insoles compared to control shoes or neutral insoles. In these two meta-analyses, a small SMD was verified in the reduction of the first and second peak of EKAM and in KAAI. For the first peak EKAM, was found an SMD $=-0.19$ ([95\% CI $0.23,-0.15], P<0.001)$ in the meta-analysis of Arnold et al. [11], an SMD $=-0.22$ ([95\% CI $-0.37,-0.07], P=$ 0.001 ) in the meta-analysis of Xing et al. [31], and in the present meta-analysis a very similar SMD $=-0.25$ ([95\% CI $-0.36,-0.13], \mathrm{P}<0.001)$. With regard to the second peak EKAM, was found an SMD $=-0.25$ ([95\% CI $0.31,-0.18], \mathrm{P}<0.001)$ in the meta-analysis of Arnold et al. [11], an SMD $=-0.26([95 \% \mathrm{CI}-0.47,-0.06], P=$ 0.01 ) in the meta-analysis of Xing et al. [31], and in the present meta-analysis an analogous value of $\mathrm{SMD}=-$ 0.26 ([95\% CI $-0.48,-0.04], P=0.02$ ). Likewise, for the KAAI, was found an SMD $=-0.14$ ([95\% CI -0.21 , 0.07], $\mathrm{P}<0.001)$ in the meta-analysis of Arnold et al. [11], an SMD $=-0.21$ ([95\% CI -0.39, - 0.02], $\mathrm{P}=0.01)$ in the meta-analysis of Xing et al. [31], and in the present meta-analysis a similar value of $\mathrm{SMD}=-0.17$ ([95\% CI $-0.31,-0.03], \mathrm{P}=0.02$ ). All three meta-analysis support an immediate effect on the reduction of the adductor moment applied at the knee with the use of lateral wedge insoles. This positive effect may be independent of the presence of a lateral arch support [31], and the presence of a neutral insole as a comparator may not be totally inert [11]. Also, as present in this meta-analysis, the effect of a higher wedge degree does not seem to be very relevant compared to lower-angle insoles. In the same way, it should not be forgotten that insoles, particularly the ones with higher degrees, are associated with some discomfort with prolonged use [47].

The main objective of this review was to understand whether the amount of the angulation of the wedge influenced the EKAM and KAAI in patients with medial knee OA. It was our hypothesis that larger angulations would lead to a higher effect. However, the effect size of insoles with wedges $\leq 5^{\circ}(\mathrm{SMD}=-0.22)$ and the effect size of insoles with wedges $>9^{\circ}(\mathrm{SMD}=-0.30)$ are very similar for the first peak and for the second peak EKAM. For KAAI, because was retrieved only one study $(n=18)$ [25] that studied insoles with a wedge greater than $9^{\circ}$, it is not possible to form any conclusion. An emerging problem that would require further analysis is related to the correct adjustment of the insoles to each patient. Apparently, there is no research investigating an optimal dose-response concerning the degree of lateral wedge insoles for each patient based on biomechanical factors. From our knowledge, only one study attempted to examine the effect of incrementally increasing lateral wedge amounts on EKAM [47]. However, a key limitation of that study was that the participants were healthy and young. The authors tested seven inclinations of lateral wedging $\left(0^{\circ}, 2^{\circ}, 4^{\circ}, 6^{\circ}, 8^{\circ}, 10^{\circ}, 12^{\circ}\right)$. Yet, it is curious that with an insole angled at $2^{\circ}$, the average reduction was surprisingly $6.4 \%$ in the first peak EKAM and 5.1\% in the KAAI, values that are similar when compared to studies with participants with medial knee OA, where insoles with angles of $5^{\circ}$ and $6^{\circ}$ are typically applied $[8,13,26]$. Some studies have attempted to apply lateral wedge insoles in a customization way but based on other indicators such as subjective comfort, pain relief, or static pedometer evaluation [16, 19, 48-50]. Their conclusions seem more promising than traditional applications based only on one degree for all individuals. In the study by Barrios et al. [48], the authors observed an increased EKAM over time ( 1 year) in the control group but not in the intervention group and, within the intervention group, the mechanical effectiveness of the lateral wedging did not decrease over time.

However, the extent of these effects remains ambiguous, with some authors suggesting that the effect size of the decrease in load on the medial compartment observed with lateral wedge insoles is too small to be clinically relevant such as reducing pain or symptoms $[15,27,51]$. On the other hand, other authors [22, 52] suggest that minor changes in knee load may have a positive effect on patients' symptoms given the number of steps taken per day (about 6500) [51]. An interesting question that has not yet been answered is whether a difference of 1 or 2 degrees in the wedge could have an impact on the biomechanical parameters and, in particular, on the patient's complaints over a long time, especially when referring to a chronic and evolutive disease with a great impact on patients' health-related quality of life [53]. We know that the biomechanical response to insoles by patients with similar characteristics presents a considerable variability.

Some limitations can be addressed to the present review, primarily the heterogeneity between the study designs and the participants. Most of the studies were single-group crossover and, from our judgment, presented an unclear 
or high risk of bias in the selection bias (random sequence generation and allocation concealment). These could be a problem because, in past years, the literature sought to identify different knee OA phenotypes $[54,55]$. The selection of participants based on biomechanical criteria included in randomized controlled trials should be the way forward, based on the prescription of biomechanical response. Another limitation is the different methodologies used in the studies to calculate EKAM. It is not clear enough in some studies how EKAM was calculated in the procedures, which may limit the comparison between studies. On the other hand, the different setup of placement of the passive markers can make comparison of the results difficult in an area that is so sensitive to small differences. Possible differences in sample size or differences in different gender elements can also be seen as a limitation in the comparison of results.

Setting the optimal angulation for each patient can contribute to improve outcomes in these patients. The results of this study may contribute to a better definition of individual angulation. Future studies should focus on optimizing the angulation of the insole and personalizing the intervention.

\section{Conclusion}

This systematic review with meta-analysis suggests that lateral wedge insoles have a small effect on reducing the forces that cross the medial knee in people with medial knee OA, regardless of the angulation applied.

The path of customization of the interventions may be the right path, and the support of clinical biomechanics may play an important role in therapeutic decisions. The analysis of biomechanical parameters may be a beneficial option for the application of lateral wedge insoles for individuals with knee OA. The optimal degree should be obtained from individual fitting with the lowest possible angle that causes an important reduction of biomechanical risks.

Given the clear biomechanical benefits, further research is needed to investigate targeted use of lateral wedge insoles in biomechanical phenotypes over a longer time to determine conclusively the effects of lateral wedge insoles.

\section{Supplementary information}

Supplementary information accompanies this paper at https://doi.org/10. 1186/s40945-019-0068-1.

Additional file 1. Risk of bias graph: review authors' judgements about each risk of bias item presented as percentages across all included studies.

Additional file 2. Risk of bias summary: review authors' judgements about each risk of bias item for each included study.

Additional file 3. Funnel plot of comparison: first peak EKAM.)
Additional file 4. Funnel plot of comparison: second peak EKAM.

Additional file 5. Funnel plot of comparison: knee adduction angular impulse (KAAl).

\section{Abbreviations}

Cl: Confidence interval; EKAM: external knee adduction moment;

GRF: Ground reaction force; K/L: Kellgren \& Lawrence scale;" KAAl: Knee adduction angular impulse; OA: Osteoarthritis; SD: Standard deviations; SMD: Standardized mean differences

\section{Authors' contributions}

Majority of presented data was gathered by VF as part of her PhD thesis. PR and LM functioned as project mentors Data collection parameters were defined by VF and RS. RSG reviewed and analyzed the data with particular attention. All authors read and approved the final manuscript.

Funding

There was no funding.

Availability of data and materials

Please contact author for data requests.

Ethics approval and consent to participate

Not applicable.

Consent for publication

Not applicable.

Competing interests

All authors have no sources of funding or any potential conflicts of interest to disclose.

\section{Author details}

${ }^{1}$ School of Health Sciences, ESSUA - School of Health, Edificio 30, University of Aveiro, 3810-193 Aveiro, Portugal. ${ }^{2}$ Santa Casa da Misericórdia da Mealhada, Aveiro, Portugal. ${ }^{3}$ Polytechnic Institute of Coimbra, Coimbra Health School, Coimbra, Portugal University of Coimbra, Centre for Health Studies and Research, Coimbra, Portugal. ${ }^{4}$ CIF2D, LABIOMEP, Faculdade de Desporto da Universidade do Porto, Coimbra, Portugal. ${ }^{5}$ CIDESD-ISMAI, INESC-TEC, LABIOMEP, Coimbra, Portugal.

Received: 28 July 2018 Accepted: 8 November 2019

Published online: 19 December 2019

References

1. Jordan KM, Arden NK, Doherty M, Bannwarth B, Bijlsma JW, Dieppe P, et al. EULAR recommendations 2003: an evidence based approach to the management of knee osteoarthritis: report of a task force of the standing Committee for International Clinical Studies Including Therapeutic Trials (ESCISIT). Ann Rheum Dis. 2003;62(12):1145-55.

2. Peat G, McCarney R, Croft P. Knee pain and osteoarthritis in older adults: a review of community burden and current use of primary health care. Ann Rheum Dis. 2001;60(2):91-7.

3. Bennell KL, Creaby MW, Wrigley TV, Bowles KA, Hinman RS, Cicuttini F, et al. Bone marrow lesions are related to dynamic knee loading in medial knee osteoarthritis. Ann Rheum Dis. 2010;69(6):1151-4.

4. Zhao D, Banks SA, Mitchell KH, D'Lima DD, Colwell CW Jr, Fregly BJ. Correlation between the knee adduction torque and medial contact force for a variety of gait patterns. J Orthop Res. 2007;25(6):789-97.

5. Wise BL, Niu J, Yang M, Lane NE, Harvey W, Felson DT, et al. Patterns of compartment involvement in tibiofemoral osteoarthritis in men and women and in whites and African Americans. Arthritis Care Res (Hoboken). 2012;64(6):847-52.

6. Schipplein $\mathrm{OD}$, Andriacchi TP. Interaction between active and passive knee stabilizers during level walking. J Orthop Res. 1991;9(1):113-9.

7. Sasaki T, Yasuda K. Clinical evaluation of the treatment of osteoarthritic knees using a newly designed wedged insole. Clin Orthop Relat Res. 1987; 221:181-7. 
8. Hinman RS, Bowles KA, Metcalf BB, Wrigley TV, Bennell KL. Lateral wedge insoles for medial knee osteoarthritis: effects on lower limb frontal plane biomechanics. Clin Biomech (Bristol, Avon). 2012;27(1):27-33.

9. Kerrigan DC, Lelas JL, Goggins J, Merriman GJ, Kaplan RJ, Felson DT. Effectiveness of a lateral-wedge insole on knee varus torque in patients with knee osteoarthritis. Arch Phys Med Rehabil. 2002:83(7):889-93.

10. Liu X, Zhang M. Redistribution of knee stress using laterally wedged insole intervention: finite element analysis of knee-ankle-foot complex. Clin Biomech. 2013;28(1):61-7.

11. Arnold JB, Wong DX, Jones RK, Hill CL, Thewlis D. Lateral wedge insoles for reducing biomechanical risk factors for medial knee osteoarthritis progression: a systematic review and meta-analysis. Arthritis Care Res (Hoboken). 2016;68(7):936-51.

12. Kakihana W, Akai M, Nakazawa K, Naito K, Torii S. Inconsistent knee varus moment reduction caused by a lateral wedge in knee osteoarthritis. American j phys med and rehabil. 2007:86(6):446-54.

13. Jones RK, Chapman GJ, Forsythe L, Parkes MJ, Felson DT. The relationship between reductions in knee loading and immediate pain response whilst wearing lateral wedged insoles in knee osteoarthritis. J Orthop Res. 2014; 32(9):1147-54.

14. Chapman GJ, Parkes MJ, Forsythe L, Felson DT, Jones RK. Ankle motion influences the external knee adduction moment and may predict who will respond to lateral wedge insoles?: an ancillary analysis from the SILK trial. Osteoarthritis and cartilage OARS Osteoarthritis Res Soc. 2015;23(8):1316-22.

15. Lewinson RT, Vallerand IA, Collins KH, Wiley JP, Lun VM, Patel C, et al. Reduced knee adduction moments for management of knee osteoarthritis:: A three month phase $1 / / 1$ randomized controlled trial. Gait Posture. 2016;50:60-8.

16. Maillefert JF, Hudry C, Baron G, Kieffert P, Bourgeois P, Lechevalier D, et al. Laterally elevated wedged insoles in the treatment of medial knee osteoarthritis: a prospective randomized controlled study. Osteoarthritis and cartilage OARS Osteoarthritis Res Soc. 2001;9(8):738-45.

17. Pham T, Maillefert JF, Hudry C, Kieffert P, Bourgeois P, Lechevalier D, et al. Laterally elevated wedged insoles in the treatment of medial knee osteoarthritis11This work was supported in part by the 'Programme Hospitalier de Recherche Clinique' (AOM 97 184) of the French health ministry. Osteoarthr Cartil. 2004;12(1):46-55.

18. Hinman RS, Bowles KA, Payne C, Bennell KL. Effect of length on laterallywedged insoles in knee osteoarthritis. Arthritis Rheum. 2008;59(1):144-7.

19. Butler RJ, Marchesi S, Royer T, Davis IS. The effect of a subject-specific amount of lateral wedge on knee mechanics in patients with medial knee osteoarthritis. J Orthop Res. 2007:25(9):1121-7.

20. Hinman RS, Bowles KA, Bennell KL. Laterally wedged insoles in knee osteoarthritis: do biomechanical effects decline after one month of wear? BMC Musculoskelet Disord. 2009;10:146.

21. Hunt MA, Takacs J, Krowchuk NM, Hatfield GL, Hinman RS, Chang R. Lateral wedges with and without custom arch support for people with medial knee osteoarthritis and pronated feet: an exploratory randomized crossover study. J Foot Ankle Res. 2017;10:20.

22. Jones RK, Chapman GJ, Findlow AH, Forsythe L, Parkes MJ, Sultan J, et al. A new approach to prevention of knee osteoarthritis: reducing medial load in the contralateral knee. J Rheumatol. 2013;40(3):309-15.

23. Nakajima K, Kakihana W, Nakagawa T, Mitomi H, Hikita A, Suzuki R, et al. Addition of an arch support improves the biomechanical effect of a laterally wedged insole. Gait Posture. 2009;29(2):208-13.

24. Abdallah AA, Radwan AY. Biomechanical changes accompanying unilateral and bilateral use of laterally wedged insoles with medial arch supports in patients with medial knee osteoarthritis. Clin Biomech. 2011;26(7):783-9.

25. Dessery $Y$, Belzile E, Turmel S, Corbeil P. Effects of foot orthoses with medial arch support and lateral wedge on knee adduction moment in patients with medial knee osteoarthritis. Prosthetics Orthot Int. 2016

26. Duivenvoorden T, van Raaij TM, Horemans HL, Brouwer RW, Bos PK, BiermaZeinstra SM, et al. Do laterally wedged insoles or valgus braces unload the medial compartment of the knee in patients with osteoarthritis? Clin Orthop Relat Res. 2015;473(1):265-74.

27. Baker K, Goggins J, Xie H, Szumowski K, LaValley M, Hunter DJ, et al. A randomized crossover trial of a wedged insole for treatment of knee osteoarthritis. Arthritis Rheum. 2007:56(4):1198-203.

28. Kakihana W, Akai M, Yamasaki N, Takashima T, Nakazawa K. Changes of joint moments in the gait of normal subjects wearing laterally wedged insoles. American j physical med and rehabil. 2004;83(4):273-8.
29. Duivenvoorden T, van Raaij TM, Horemans HL, Brouwer RW, Bos PK, BiermaZeinstra SM, et al. Do laterally wedged insoles or Valgus braces unload the medial compartment of the knee in patients with osteoarthritis? Clin Orthop Relat Res. 2014:1-10.

30. Arnold JB. Lateral wedge insoles for people with medial knee osteoarthritis: one size fits all, some or none? Osteoarthritis and cartilage OARS Osteoarthritis Res Soc. 2016;24(2):193-5.

31. Xing F, Lu B, Kuang MJ, Wang Y, Zhao YL, Zhao J, et al. A systematic review and meta-analysis into the effect of lateral wedge arch support insoles for reducing knee joint load in patients with medial knee osteoarthritis. Medicine. 2017;96(24):e7168.

32. Liberati A, Altman DG, Tetzlaff J, Mulrow C, Gotzsche PC, loannidis JP, et al. The PRISMA statement for reporting systematic reviews and meta-analyses of studies that evaluate health care interventions: explanation and elaboration. Ann Intern Med. 2009;151(4):W65-94.

33. Schardt C, Adams MB, Owens T, Keitz S, Fontelo P. Utilization of the PICO framework to improve searching PubMed for clinical questions. BMC Med Inform Decis Mak. 2007;7:16.

34. Higgins JP, Altman DG, Gotzsche PC, Juni P, Moher D, Oxman AD, et al. The Cochrane Collaboration's tool for assessing risk of bias in randomised trials. BMJ. 2011;343:d5928.

35. Lipsey MW, Wilson DB. Practical meta-analysis: SAGE publications, Inc; 2001.

36. Borenstein $M$, Hedges LV, Higgins JP, Rothstein HR. A basic introduction to fixed-effect and random-effects models for meta-analysis. Res Synth Methods. 2010;1(2):97-111.

37. Higgins JP, Thompson SG. Quantifying heterogeneity in a meta-analysis. Stat Med. 2002;21(11):1539-58

38. Higgins JP, Thompson SG, Deeks JJ, Altman DG. Measuring inconsistency in meta-analyses. BMJ. 2003;327(7414):557-60.

39. Duval S, Tweedie R. Trim and fill: a simple funnel-plot-based method of testing and adjusting for publication bias in meta-analysis. Biometrics. 2000; 56(2):455-63.

40. Maly MR, Culham EG, Costigan PA. Static and dynamic biomechanics of foot orthoses in people with medial compartment knee osteoarthritis. Clin Biomech (Bristol, Avon). 2002;17(8):603-10.

41. Kakihana W, Akai M, Nakazawa K, Takashima T, Naito K, Torii S. Effects of laterally wedged insoles on knee and subtalar joint moments. Arch Phys Med Rehabil. 2005:86(7):1465-71.

42. Shimada S, Kobayashi S, Wada M, Uchida K, Sasaki S, Kawahara H, et al. Effects of disease severity on response to lateral wedged shoe insole for medial compartment knee osteoarthritis. Arch Phys Med Rehabil. 2006; 87(11):1436-41.

43. Hinman RS, Payne C, Metcalf BR, Wrigley TV, Bennell KL. Lateral wedges in knee osteoarthritis: what are their immediate clinical and biomechanical effects and can these predict a three-month clinical outcome? Arthritis Rheum. 2008:59(3):408-15.

44. Fantini Pagani $\mathrm{CH}$, Hinrichs M, Bruggemann GP. Kinetic and kinematic changes with the use of valgus knee brace and lateral wedge insoles in patients with medial knee osteoarthritis. J Orthop Res. 2012;30(7):1125-32.

45. Hatfield GL, Cochrane CK, Takacs J, Krowchuk NM, Chang R, Hinman RS, et al. Knee and ankle biomechanics with lateral wedges with and without a custom arch support in those with medial knee osteoarthritis and flat feet. J Orthop Res. 2016;34(9):1597-605.

46. Kellgren JH, Lawrence JS. Radiological assessment of osteo-arthrosis. Ann Rheum Dis. 1957;16(4):494-502.

47. Tipnis RA, Anloague PA, Laubach LL, Barrios JA. The dose-response relationship between lateral foot wedging and the reduction of knee adduction moment. Clin Biomech (Bristol, Avon). 2014;29(9):984-9.

48. Barrios JA, Butler RJ, Crenshaw JR, Royer TD, Davis IS. Mechanical effectiveness of lateral foot wedging in medial knee osteoarthritis after 1 year of wear. J Orthop Res. 2013;31(5):659-64.

49. Butler RJ, Barrios JA, Royer T, Davis IS. Effect of laterally wedged foot orthoses on rearfoot and hip mechanics in patients with medial knee osteoarthritis. Prosthetics Orthot Int. 2009;33(2):107-16.

50. Moyer RF, Birmingham TB, Dombroski CE, Walsh RF, Leitch KM, Jenkyn TR, et al. Combined effects of a valgus knee brace and lateral wedge foot orthotic on the external knee adduction moment in patients with varus gonarthrosis. Arch Phys Med Rehabil. 2013:94(1):103-12.

51. Bennell KL, Bowles KA, Payne C, Cicuttini F, Williamson E, Forbes A, et al. Lateral wedge insoles for medial knee osteoarthritis: 12 month randomised controlled trial. BMJ. 2011;342:d2912. 
52. Farrokhi S, Voycheck CA, Tashman S, Fitzgerald GK. A biomechanical perspective on physical therapy management of knee osteoarthritis. J orthop and sports phys ther. 2013;43(9):600-19.

53. Picavet $\mathrm{HS}$, Hoeymans $\mathrm{N}$. Health related quality of life in multiple musculoskeletal diseases: SF-36 and EQ-5D in the DMC3 study. Ann Rheum Dis. 2004;63(6):723-9.

54. lijima H, Fukutani N, Aoyama T, Fukumoto T, Uritani D, Kaneda E, et al. Clinical phenotype classifications based on static Varus alignment and Varus thrust in Japanese patients with medial knee osteoarthritis. Arthritis Rheumatol. 2015;67(9):2354-62.

55. van der Esch M, Knoop J, van der Leeden M, Roorda LD, Lems WF, Knol DL, et al. Clinical phenotypes in patients with knee osteoarthritis: a study in the Amsterdam osteoarthritis cohort. Osteoarthritis and cartilage OARS Osteoarthritis Res Soc. 2015;23(4):544-9.

\section{Publisher's Note}

Springer Nature remains neutral with regard to jurisdictional claims in published maps and institutional affiliations.

Ready to submit your research? Choose BMC and benefit from:

- fast, convenient online submission

- thorough peer review by experienced researchers in your field

- rapid publication on acceptance

- support for research data, including large and complex data types

- gold Open Access which fosters wider collaboration and increased citations

- maximum visibility for your research: over $100 \mathrm{M}$ website views per year

At BMC, research is always in progress.

Learn more biomedcentral.com/submissions 